University of Nebraska - Lincoln

DigitalCommons@University of Nebraska - Lincoln

Architectural Engineering -- Faculty Publications

Architectural Engineering and Construction,

Durham School of

3-2013

Relationships between unoccupied classroom acoustical conditions and elementary student achievement measured in eastern Nebraska

Lauren M. Ronsse

University of Nebraska - Lincoln, Ironsse@unl.edu

Lily M. Wang

University of Nebraska - Lincoln, Iwang4@unl.edu

Follow this and additional works at: https://digitalcommons.unl.edu/archengfacpub

Part of the Acoustics, Dynamics, and Controls Commons, and the Architectural Engineering Commons

Ronsse, Lauren M. and Wang, Lily M., "Relationships between unoccupied classroom acoustical conditions and elementary student achievement measured in eastern Nebraska" (2013). Architectural Engineering -- Faculty Publications. 57.

https://digitalcommons.unl.edu/archengfacpub/57

This Article is brought to you for free and open access by the Architectural Engineering and Construction, Durham School of at DigitalCommons@University of Nebraska - Lincoln. It has been accepted for inclusion in Architectural Engineering -- Faculty Publications by an authorized administrator of DigitalCommons@University of Nebraska Lincoln. 


\title{
Relationships between unoccupied classroom acoustical conditions and elementary student achievement measured in eastern Nebraska
}

\author{
Lauren M. Ronsse ${ }^{\text {a) }}$ and Lily M. Wang \\ Durham School of Architectural Engineering and Construction, University of Nebraska-Lincoln, \\ 1110 South 67th Street, Omaha, Nebraska 68182-0816
}

(Received 26 October 2011; revised 8 January 2013; accepted 9 January 2013)

\begin{abstract}
Building standards recommend maximum background noise levels (BNL) and reverberation times (RT) for unoccupied classrooms. However, existing research does not show a consistent correlation between these parameters and student achievement. Through in situ testing, this research seeks to determine what acoustical conditions should be attained in elementary schools for students to meet educational goals. Acoustical measurements were conducted in a Nebraska public school system and correlated to achievement scores from students in the surveyed classrooms. Unoccupied BNLs and RTs were gathered in 34 third and 33 fifth-grade classrooms. Additionally, binaural room impulse response measurements were gathered in a subset of the classrooms. The results suggest that student reading and language subject areas may be negatively impacted by higher unoccupied BNLs; to meet the upper half of NE state targets, these levels should be less than $45 \mathrm{dBA}$. However, the percentage of students receiving free or reduced price lunches is more strongly correlated to achievement than BNLs, and the negative correlations between noise and achievement are not significant when controlling for this demographic variable. One statistically significant relationship that remained when controlling for demographics was that classrooms with lower distortion of frequency-smoothed magnitude values generally had students with higher language scores.
\end{abstract}

(C) 2013 Acoustical Society of America. [http://dx.doi.org/10.1121/1.4789356]

PACS number(s): 43.50.Qp, 43.55.Hy [SF]

Pages: 1480-1495

\section{INTRODUCTION}

The importance of enhancing education for school children is widely recognized, and in the United States, ANSI S12.60 "Acoustical Performance Criteria, Design Requirements, and Guidelines for Schools, Part 1: Permanent Schools" sets the standard for desired classroom acoustical conditions (ANSI, 2010), based on extensive research indicating what required signal-to-noise ratios (SNR) should be to optimize speech intelligibility (Houtgast, 1981; Bradley et al., 1999; Jamieson et al., 2004). How aspects of classroom environments are related to student achievement, though, are not as clearly defined. Research has shown that the physical characteristics of classrooms are one of many contributing factors that may impact elementary student learning (Lanham, 1999). Specifically, higher background noise levels (BNL) have been found to be significantly correlated to lower student achievement scores both in occupied classrooms (Dockrell and Shield, 2006; Shield and Dockrell, 2008) and unoccupied ones (Ronsse and Wang, 2010). Since it is more straightforward to design buildings to meet unoccupied BNL guidelines, this paper presents a more comprehensive study on how unoccupied BNL is correlated to student learning, removing some limitations of the Ronsse and Wang (2010) study.

\footnotetext{
a) Author to whom correspondence should be addressed. Current Affiliation: Columbia College Chicago, Department of Audio Arts and Acoustics, 33 E. Congress Parkway, Chicago, IL 60605. Electronic mail: 1ronsse@colum.edu
}

The current ANSI S12.60 Standard on classroom acoustics recommends a maximum unoccupied BNL of $35 \mathrm{dBA}$ and $55 \mathrm{dBC}$ for classrooms with single mode HVAC systems (ANSI, 2010). For classrooms containing multiple mode HVAC systems, a maximum BNL of $37 \mathrm{dBA}$ and $57 \mathrm{dBC}$ is allowed by the standard. The BNLs specified in this standard are based on signal-to-noise ratio conditions necessary for good speech intelligibility by a broad range of occupants, including younger students and those with mild to moderate hearing impairments, as evidenced from many studies (Finitzo-Hieber and Tillman, 1978; Elliott, 1979). More recently, Bradley and Sato (2008) conducted speech recognition tests in 41 elementary school classrooms containing students ranging from 6 to 11 years old. The researchers found that a minimum SNR of approximately $+20 \mathrm{~dB}$ was required for the youngest students to achieve $95 \%$ speech intelligibility or better. For typical teacher voice levels of approximately $60 \mathrm{dBA}$, the occupied BNL should be a maximum of 40 $\mathrm{dBA}$ then to obtain a SNR required for good speech intelligibility for young students (Bradley and Sato, 2008). Measurements in classrooms indicate occupied noise levels are on average $5 \mathrm{dBA}$ greater than unoccupied BNLs, and occupied noise levels tend to increase with higher levels of ambient noise from building systems and other sources (Sato and Bradley, 2008).

Noise levels exceeding $40 \mathrm{dBA}$ have been measured in numerous elementary school classrooms, though. Picard and Bradley (2001) provide a summary of published noise level data in classrooms. This summary reports ambient noise levels with students engaged in normal quiet activity ranging 
from 52 to $75 \mathrm{dBA}$ in elementary school classrooms. Unoccupied BNLs ranging from 34 to $66 \mathrm{dBA}$ were measured in 32 elementary classrooms in central Ohio, USA (Knecht et al., 2002); all of the measurements of noise levels below $50 \mathrm{dBA}$ were acquired with the heating, ventilating, and airconditioning (HVAC) systems off.

Shield and Dockrell (2004) conducted noise level measurements in 30 unoccupied classrooms in primary schools in the UK. This study reports an average equivalent noise level $\left(\mathrm{L}_{\mathrm{Aeq}}\right)$ of $47 \mathrm{dBA}$ and an average level exceeded $90 \%$ of the time $\left(\mathrm{L}_{\mathrm{A} 90}\right)$ of $37 \mathrm{dBA}$. For these measurements, the heating system was operating in only seven of the 30 classrooms. Acoustical measurements were conducted in 47 primary school classrooms in Hong Kong with quiet students present (Choi and McPherson, 2005). The average noise level among all of the classrooms was $61 \mathrm{dBA}$, with a range from 54 to $68 \mathrm{dBA}$. The research documents high BNLs in existing elementary or primary school classrooms.

Klatte et al. (2007) conducted a series of experiments to test the effects of interfering speech and traffic noise on speech perception and cognitive performance. This research showed negative effects of background speech on these tasks. A follow-up study investigated the effects of background speech, typical classroom background noise generated by students, and room reverberation on the speech perception and listening comprehension of both children and adults (Klatte et al., 2010b). This study found classroom noise had a negative effect on the children's speech perception and background speech had a negative effect on the children's listening comprehension. Long reverberation times also heightened these negative effects. However, these studies were conducted in laboratory environments and did not include investigations of background mechanical system noise. Therefore, additional research in classrooms with HVAC noise is needed.

While high noise levels do negatively impact speech intelligibility and perception, the effect of BNL on student learning and achievement has not been as well documented. Shield and Dockrell (2008) explored relationships between both occupied and unoccupied noise levels in primary schools and student performance on achievement tests. The researchers found a significant negative correlation between occupied noise levels in classrooms and achievement test results. The English test scores for the older students (approximately 11 years old) were significantly correlated to occupied noise levels. Also, government targets for literacy and numeracy were not met in classrooms with occupied $\mathrm{L}_{\mathrm{A} 90}$ values above $50 \mathrm{dBA}$. However, this study did not find significant correlations between student achievement and unoccupied $\mathrm{L}_{\mathrm{Aeq}}$ values in classrooms. Therefore, unoccupied BNLs required to meet government targets for achievement could not be determined from this study. The unoccupied BNL measurements were conducted under inconsistent mechanical system operating conditions, though.

Ronsse and Wang (2010) investigated the impacts of unoccupied BNLs on student learning in elementary schools in IA, USA. This study found that lower student reading comprehension scores were significantly correlated to higher unoccupied BNLs, and that the maximum allowable BNL to meet state targets for acceptable student achievement in this area was $41 \mathrm{dBA}$. However, the BNLs were gathered with the classroom mechanical systems operating only in the cooling mode, and achievement scores were reported by the participating school district as averages per grade level at a school rather than per classroom. Therefore, more work is required to clearly determine how unoccupied BNL requirements, such as those listed in the ANSI S12.60 Standard (ANSI, 2010), are correlated to student achievement.

With regards to reverberation time (RT), the ANSI S12.60 Standard also specifies that core learning spaces with volumes less than $283 \mathrm{~m}^{3}$ should have a maximum RT of $0.6 \mathrm{~s}$ in each octave band from 500 to $2000 \mathrm{~Hz}$ (ANSI, 2010). While excessive reverberation may smear speech sources adversely affecting speech intelligibility (Bistafa and Bradley, 2000), speech perception, and short-term memory (Klatte et al., 2010a), research comparing unoccupied RTs in existing classrooms to longer term student learning and achievement is lacking. In fact, some reverberation is believed to be beneficial in rooms, particularly with regards to early reflections that reinforce the direct sound. This may increase the level of the direct sound, improving speech intelligibility in the space (Bradley et al., 2003). Hodgson and Nosal (2002) emphasize the importance of considering the interaction of BNL on the resulting RT for optimal speech intelligibility. Their research suggests that longer RTs may be desired in spaces with higher BNLs for adequate speech intelligibility.

Reverberation times have been documented in numerous existing classrooms. Bradley (1986) measured RTs ranging from 0.39 to $1.20 \mathrm{~s}$ in the $1000 \mathrm{~Hz}$ octave band in ten occupied classrooms in Ottawa, Canada. The RTs in 32 unoccupied classrooms in Ohio, USA, were found to range from about 0.32 to $1.27 \mathrm{~s}$ (Knecht et al., 2002). Both occupied and unoccupied RT measurements were conducted in eight secondary school classrooms in Italy (Astolfi and Pellerey, 2008). The occupied RT values averaged across the 500,1000 , and $2000 \mathrm{~Hz}$ octave bands ranged from 0.6 to $1.4 \mathrm{~s}$, and the unoccupied RT values averaged across the 500,1000 , and $2000 \mathrm{~Hz}$ octave bands ranged from 0.9 to $2.6 \mathrm{~s}$.

Yang and Bradley (2009) performed listening tests on school children with headphones under simulated classroom conditions with varying reverberation times. Their results suggest that elementary school classrooms should have reverberation times ranging from 0.3 to $0.9 \mathrm{~s}$ to create an acoustical environment necessary for adequate speech intelligibility. Comparisons between student achievement and RT for classrooms with this range are still needed.

In addition to BNL and RT, other acoustical metrics may relate to student achievement, particularly those that focus on quantifying the perception of sound by the human ear. Some of these metrics, such as the speech transmission index (STI) (Houtgast and Steeneken, 1985) and distortion of frequency-smoothed magnitude (DFSM) (Shinn-Cunningham et al., 2005) were introduced as monaural metrics. The STI is a one-number rating that reflects the negative effects of high BNL on speech intelligibility, calculated from the 
modulation transfer function. This metric gives more weight to the SNR occurring in octave bands more important for understanding speech. The DFSM conveys spectral smearing of the incoming signal due to room reverberation (ShinnCunningham et al., 2005). If the signal is highly distorted in the frequency domain when it reaches the ear, then the listener may not be able to perceive the correct source location. Calculated from the room frequency response, the DFSM compares the reverberant signal to a corresponding "pseudoanechoic" signal from which all room reflections have been removed. The absolute value of the difference in level between the reverberant and pseudo-anechoic frequency response is calculated in each one-third octave band. The mean of this difference is the DFSM. DFSM was included in this study because it gauges ease of source localization, which may be an important part of the learning process for young children. A more reverberant space produces higher DFSM values, indicating greater difficulty in localizing sound sources. How does this metric correlate to student achievement scores, in comparison to BNL and RT?

The auditory system uses the information it receives in both ears to fully process and understand incoming signals, though (Moore, 2004). Therefore, binaural acoustical metrics, including interaural cross-correlations (early) $\left(\mathrm{IACC}_{\mathrm{E}}\right.$ ) and interaural level differences (ILD), have been developed to quantify the signal as it is perceived by both ears. Also, differences between the left and right ear monaural perception-based metrics quantify any differences occurring in the signal between the two ears, which may relate to how the signal is processed by the brain.

Research investigating the impact of monaural and interaural spectral cues on source localization has been conducted (Jin et al., 2004). Their results show that reliable interaural spectral cues are not sufficient for localization when the two ears are receiving signals with very different spectral content. Also, their outcomes indicate that a listener cannot use monaural spectral cues to correctly locate the source if interaural spectral cues do not exist.

Shinn-Cunningham et al. (2005) performed binaural room impulse response measurements in a typical classroom for varying receiver positions and nearby source distances, up to $1 \mathrm{~m}$ away from the source. The mean absolute difference between the reverberant and pseudo-anechoic measurements reported in this study range from approximately 0 to $10 \mathrm{~dB}$ (re: Anechoic), and higher DFSMs occurred for measurement configurations with strong early reflections present. Differences between the left and right ear DFSM may be calculated to quantify the similarity of the distortion of the spectral content perceived between the two ears. The present research will relate differences between the left and right ear DFSM to standardized student achievement scores, which may indicate how differences in DFSM between the two ears impact the listener's ability to determine the correct source location.

Research considering relationships between these additional perception-based metrics and student achievement is lacking. Also, previous research has not shown what unoccupied reverberation times and background noise levels should be attained in classrooms for optimal student learning, though these criteria are specified in building standards. Particularly noise generated by classroom mechanical systems has not been thoroughly documented and related to student achievement. This paper addresses these gaps in earlier studies by comparing unoccupied RT and BNL to student achievement. The operating conditions of the classroom mechanical systems were monitored and regulated for the BNL measurements, so that noise levels typically occurring during the school day could be assessed. Additionally, the present study compares various perception-based acoustical metrics to student achievement, which has not been done previously.

The goal of this study is to relate both standard and perception-based unoccupied classroom acoustical metrics to student achievement to determine how classroom acoustics might impact student learning. This research was conducted in 14 elementary schools in the Papillion-La Vista public school system in northeastern NE in the United States. Acoustical measurements were made in third and fifth-grade classrooms in these schools and correlated to the standardized student achievement test results from students in the surveyed classrooms.

\section{METHODS}

An acoustical survey of the third and fifth-grade classrooms in the Papillion-La Vista School District was conducted from January through May 2010. The third-grade students are typically 8 to 9 years-old, and the fifth-grade students are typically 10 to 11 years-old. Sixty-seven classrooms were included in the study.

\section{A. Site visit procedures}

Detailed notes and photographs were taken in each space to document the room architectural features, furnishings, and prominent noise sources. Unoccupied background noise level (BNL) and reverberation time (RT) measurements were gathered in each classroom. Unoccupied binaural room impulse response (BRIR) measurements were also gathered in a select group of 20 classrooms, including ten classrooms at each grade level. All perimeter windows and doors were closed before the start of each acoustical measurement.

\section{B. Classroom descriptions}

Most of the classrooms had a traditional, closed floor plan design. However, some of the classrooms had an open floor plan design, wherein wall or door openings to adjacent spaces were present. Also, one of the classrooms was a portable unit, separate from the rest of the school building. The floor plan types are shown in Tables I and II for the third and fifth-grade classrooms, respectively. In these tables, classrooms with the same number designation were located in the same school building. The room finishes typically included acoustical ceiling tile, hard wall surfaces of gypsum wall board or concrete masonry unit, and thin carpet on the floor. The classrooms were furnished with desks, chairs, chalkboards or whiteboards, tack-boards, cabinets, and shelves. 
TABLE I. Floor plan types, standardized achievement scores, and demographic data for students in the third-grade classrooms.

\begin{tabular}{|c|c|c|c|c|c|c|}
\hline \multirow[b]{2}{*}{ Room } & \multirow[b]{2}{*}{ Floor Plan Type ${ }^{a}$} & \multicolumn{3}{|c|}{ Terra Nova Achievement Scores } & \multirow[b]{2}{*}{$\begin{array}{c}\text { State Accountability Reading Scores } \\
\text { (Scale Score) }\end{array}$} & \multirow[b]{2}{*}{$\begin{array}{c}\text { Free or Reduced-Price } \\
\text { Lunches }(\%)\end{array}$} \\
\hline & & Math (NCE) & $\begin{array}{c}\text { Language } \\
\text { (Percentile Rank) }\end{array}$ & Reading (NCE) & & \\
\hline $1 \mathrm{~A}$ & $\mathrm{O}$ & 63 & 55 & 65 & 116 & 4 \\
\hline $2 \mathrm{~A}^{\mathrm{b}}$ & $\mathrm{C}$ & 52 & 46 & 51 & 89 & 7 \\
\hline $2 \mathrm{~B}^{\mathrm{b}}$ & $\mathrm{C}$ & 64 & 73 & 67 & 113 & 12 \\
\hline $3 \mathrm{~A}$ & $\mathrm{C}$ & 47 & 35 & 50 & 86 & 47 \\
\hline $3 \mathrm{~B}^{\mathrm{b}}$ & $\mathrm{C}$ & 55 & 50 & 59 & 103 & 42 \\
\hline $3 \mathrm{C}$ & $\mathrm{C}$ & 50 & 41 & 52 & 88 & 31 \\
\hline $4 \mathrm{~A}$ & $\mathrm{C}$ & 52 & 46 & 62 & 100 & 64 \\
\hline $4 \mathrm{~B}$ & $\mathrm{C}$ & 49 & 44 & 59 & 108 & 50 \\
\hline $5 \mathrm{~A}^{\mathrm{b}}$ & $\mathrm{O}$ & 63 & 58 & 60 & 117 & 29 \\
\hline $5 \mathrm{~B}^{\mathrm{b}}$ & $\mathrm{O}$ & 55 & 48 & 64 & 103 & 31 \\
\hline $6 \mathrm{~A}$ & $\mathrm{C} / \mathrm{O}$ & 58 & 60 & 59 & 102 & 17 \\
\hline $6 B$ & $\mathrm{C} / \mathrm{O}$ & 64 & 59 & 59 & 121 & 24 \\
\hline 7A & $\mathrm{C}$ & 45 & 33 & 46 & 80 & 68 \\
\hline $7 B$ & $\mathrm{C}$ & 45 & 44 & 57 & 99 & 48 \\
\hline $8 \mathrm{~A}$ & $\mathrm{C}$ & 47 & 42 & 49 & 86 & 44 \\
\hline $8 B$ & $\mathrm{C}$ & 58 & 48 & 59 & 96 & 50 \\
\hline $8 \mathrm{C}$ & $\mathrm{C}$ & 53 & 49 & 54 & 91 & 35 \\
\hline $9 \mathrm{~A}$ & $\mathrm{C}$ & 65 & 64 & 74 & 124 & 4 \\
\hline $9 B^{b}$ & $\mathrm{C}$ & 66 & 66 & 68 & 124 & 12 \\
\hline $10 \mathrm{~A}$ & $\mathrm{C}$ & 61 & 61 & 64 & 101 & 6 \\
\hline $10 \mathrm{~B}$ & $\mathrm{C}$ & 60 & 61 & 64 & 100 & 0 \\
\hline $10 \mathrm{C}$ & $\mathrm{C}$ & 64 & 61 & 70 & 125 & 10 \\
\hline $10 \mathrm{D}$ & $\mathrm{C}$ & 57 & 51 & 58 & 102 & 6 \\
\hline $11 \mathrm{~A}^{\mathrm{b}}$ & $\mathrm{C}$ & 60 & 47 & 59 & 117 & 11 \\
\hline 11B & $\mathrm{C}$ & 65 & 55 & 63 & 121 & 5 \\
\hline $11 C^{b}$ & $\mathrm{C}$ & 50 & 43 & 56 & 105 & 0 \\
\hline $12 \mathrm{~A}$ & $\mathrm{P}$ & 53 & 58 & 59 & 92 & 27 \\
\hline $12 \mathrm{~B}^{\mathrm{b}}$ & $\mathrm{C}$ & 55 & 54 & 63 & 105 & 38 \\
\hline $12 \mathrm{C}$ & $\mathrm{C} / \mathrm{O}$ & 67 & 73 & 70 & 131 & 17 \\
\hline $13 \mathrm{~A}$ & $\mathrm{C}$ & 48 & 49 & 55 & 101 & 22 \\
\hline 13B & $\mathrm{C}$ & 72 & 59 & 68 & 110 & 16 \\
\hline $13 \mathrm{C}$ & $\mathrm{C}$ & 66 & 59 & 64 & 105 & 21 \\
\hline $14 \mathrm{~A}$ & $\mathrm{C}$ & 67 & 61 & 63 & 122 & 25 \\
\hline $14 \mathrm{~B}^{\mathrm{b}}$ & $\mathrm{C}$ & 52 & 44 & 54 & 108 & 24 \\
\hline
\end{tabular}

${ }^{\mathrm{a}}$ Floor Plan Types: $\mathrm{C}=$ closed plan; $\mathrm{O}=$ open plan; $\mathrm{C} / \mathrm{O}=$ closed plan with open door; $\mathrm{P}=$ portable.

${ }^{\mathrm{b}}$ Classrooms selected for BRIR measurements.

Most of the rooms were both heated and cooled by central mechanical systems. The temperature set points were controlled remotely. Cooling in five of the classrooms (4A, 4B, 4C, 4D, and 4E) was provided by window airconditioning units. These units automatically turned on and off as necessary to meet the temperature set point. All of the mechanical systems were set to operate in the cooling mode if the outdoor air temperature was above $12.8^{\circ} \mathrm{C}\left(55^{\circ} \mathrm{F}\right)$. If the outdoor air temperature was below $12.8{ }^{\circ} \mathrm{C}\left(55^{\circ} \mathrm{F}\right)$, the mechanical systems should have been operating in the heating mode. The central mechanical systems were set to operate in either of these modes, not in the off or idle condition, while the classrooms were occupied; consequently acoustics measurements were taken only in the operating conditions.

\section{Background noise level measurement procedures}

Equivalent A-weighted sound levels $\left(\mathrm{L}_{\mathrm{Aeq}}\right)$ were gathered with reference to $20 \mu \mathrm{Pa}$ over a 5 min continuous time period in each unoccupied classroom via a Larson Davis 824 sound level meter. The meter was mounted on a tripod, with the microphone approximately $1.1 \mathrm{~m}$ above the ground. The meter was placed in the approximate center of each classroom for the primary measurement location. The measurement personnel subjectively determined if the unoccupied sound level was significantly different from the center of the room in other room locations. If differences were apparent, the measurement was repeated in those locations, and an energy average of the sound pressure levels was taken to obtain an average BNL for the space.

The BNL measurements were conducted in each classroom with the mechanical systems operating in both the heating and cooling modes. To quantify the number of days the mechanical systems were operating in each mode throughout the school year, from August 2009 to May 2010, weather data from two nearby weather stations were collected. If the average outdoor air temperature for the day was above $12.8^{\circ} \mathrm{C}\left(55^{\circ} \mathrm{F}\right)$, it was assumed the mechanical 
TABLE II. Floor plan types, standardized achievement scores, and demographic data for students in the fifth-grade classrooms.

\begin{tabular}{|c|c|c|c|c|c|c|}
\hline \multirow[b]{2}{*}{ Room } & \multirow[b]{2}{*}{ Floor Plan Type ${ }^{\mathrm{a}}$} & \multicolumn{3}{|c|}{ Terra Nova Achievement Scores } & \multirow{2}{*}{$\begin{array}{l}\text { State Accountability Reading } \\
\text { Scores (Scale Score) }\end{array}$} & \multirow{2}{*}{$\begin{array}{c}\text { Free or Reduced-Price } \\
\text { Lunches }(\%)\end{array}$} \\
\hline & & Math (NCE) & Language (Percentile Rank) & Reading (NCE) & & \\
\hline $1 \mathrm{~B}$ & $\mathrm{C}$ & 68 & 76 & 68 & 131 & 0 \\
\hline $1 \mathrm{C}^{\mathrm{b}}$ & $\mathrm{C}$ & 53 & 59 & 51 & 93 & 29 \\
\hline $2 \mathrm{C}$ & $\mathrm{C}$ & 51 & 61 & 57 & 115 & 13 \\
\hline $2 \mathrm{D}$ & $\mathrm{C}$ & 65 & 73 & 69 & 129 & 0 \\
\hline $3 \mathrm{D}$ & $\mathrm{C}$ & 50 & 47 & 52 & 84 & 29 \\
\hline $3 \mathrm{E}$ & $\mathrm{C}$ & 62 & 69 & 61 & 119 & 24 \\
\hline $3 \mathrm{~F}$ & $\mathrm{C}$ & 49 & 57 & 51 & 101 & 32 \\
\hline $4 C$ & $\mathrm{C}$ & 58 & 53 & 57 & 109 & 29 \\
\hline $4 \mathrm{D}$ & $\mathrm{C}$ & 51 & 41 & 51 & 95 & 53 \\
\hline $4 \mathrm{E}$ & $\mathrm{C}$ & 38 & 46 & 47 & 87 & 44 \\
\hline $5 \mathrm{C}$ & $\mathrm{O}$ & 52 & 50 & 51 & 86 & 47 \\
\hline $5 \mathrm{D}^{\mathrm{b}}$ & $\mathrm{O}$ & 49 & 60 & 56 & 112 & 39 \\
\hline $6 C$ & $\mathrm{C} / \mathrm{O}$ & 59 & 76 & 61 & 111 & 9 \\
\hline $6 \mathrm{D}$ & $\mathrm{C} / \mathrm{O}$ & 57 & 75 & 61 & 121 & 9 \\
\hline $7 C^{b}$ & $\mathrm{C}$ & 47 & 47 & 53 & 93 & 64 \\
\hline $7 D^{b}$ & $\mathrm{C}$ & 46 & 47 & 50 & 78 & 40 \\
\hline $8 \mathrm{D}$ & $\mathrm{C}$ & 50 & 71 & 60 & 121 & 24 \\
\hline $8 \mathrm{E}$ & $\mathrm{C}$ & 51 & 63 & 56 & 97 & 29 \\
\hline $8 \mathrm{~F}$ & $\mathrm{C}$ & 55 & 65 & 60 & 116 & 25 \\
\hline $9 C^{b}$ & $\mathrm{C}$ & 63 & 70 & 62 & 125 & 0 \\
\hline 9D & $\mathrm{C}$ & 64 & 64 & 56 & 119 & 4 \\
\hline $10 \mathrm{E}$ & $\mathrm{C}$ & 70 & 77 & 64 & 127 & 3 \\
\hline $10 \mathrm{~F}$ & $\mathrm{C}$ & 64 & 69 & 63 & 115 & 3 \\
\hline 11D & $\mathrm{C}$ & 62 & 71 & 60 & 108 & 0 \\
\hline $11 \mathrm{E}^{\mathrm{b}}$ & $\mathrm{C}$ & 65 & 65 & 60 & 117 & 13 \\
\hline $11 \mathrm{~F}$ & $\mathrm{C}$ & 57 & 69 & 55 & 106 & 16 \\
\hline $12 \mathrm{D}^{\mathrm{b}}$ & $\mathrm{C} / \mathrm{O}$ & 49 & 55 & 51 & 90 & 35 \\
\hline $12 \mathrm{E}^{\mathrm{b}}$ & $\mathrm{C} / \mathrm{O}$ & 59 & 63 & 57 & 124 & 15 \\
\hline $13 \mathrm{D}^{\mathrm{b}}$ & $\mathrm{C}$ & 61 & 61 & 58 & 114 & 28 \\
\hline $13 \mathrm{E}^{\mathrm{b}}$ & $\mathrm{C}$ & 64 & 65 & 64 & 125 & 17 \\
\hline $13 \mathrm{~F}$ & $\mathrm{C} / \mathrm{O}$ & 54 & 53 & 54 & 100 & 6 \\
\hline $14 \mathrm{C}$ & $\mathrm{C}$ & 52 & 54 & 54 & 102 & 11 \\
\hline $14 \mathrm{D}$ & $\mathrm{C}$ & 61 & 64 & 62 & 126 & 5 \\
\hline
\end{tabular}

${ }^{\mathrm{a}}$ Floor Plan Types: $\mathrm{C}=$ closed plan; $\mathrm{O}=$ open plan; $\mathrm{C} / \mathrm{O}=$ closed plan with open door.

${ }^{\mathrm{b}}$ Classrooms selected for BRIR measurements.

systems were operating in the cooling mode for that day. Otherwise, the mechanical systems were assumed to be operating in the heating mode for the day. The mechanical system operating conditions were used to quantify the temperature-weighted daily-average BNLs in the classrooms throughout the school year as described in Sec. III A.

\section{Reverberation time measurement procedures}

The unoccupied RT was gathered in all of the classrooms using a balloon pop impulse response method (similar to that described in ISO 3382 (International Organization for Standardization, 2008), to expedite the rate at which data could be gathered in the large number of classrooms surveyed. The balloons were inflated to the same size, about $0.76 \mathrm{~m}$ circumference, for each measurement to improve the impulse repeatability. The balloon was popped using a sharp metal pin, and the resulting impulse response was recorded by the Larson Davis 824 sound level meter in the center of the room. The $\mathrm{T}_{20}$ value was calculated in each octave band from 125 to $8000 \mathrm{~Hz}$ by the Larson Davis 824 - Utility software. The $\mathrm{T}_{20}$ values are reported since the balloon pop impulses did not generate enough energy at low frequencies to calculate accurate $\mathrm{T}_{30}$ values.

\section{E. Binaural room impulse response measurement procedures}

BRIR measurements were gathered in 20 of the classrooms. These classrooms were selected due to their wide range in BNL and $\mathrm{RT}$, relative to the sample of surveyed classrooms. Also, classrooms with mechanical systems that generated similar noise levels in the heating and cooling modes were chosen. The classrooms selected for the BRIR measurements are noted in Tables I and II.

BRIR measurements were gathered in 16 different measurement configurations in each classroom, with source rotations and receiver positions as shown in Fig. 1. For each 


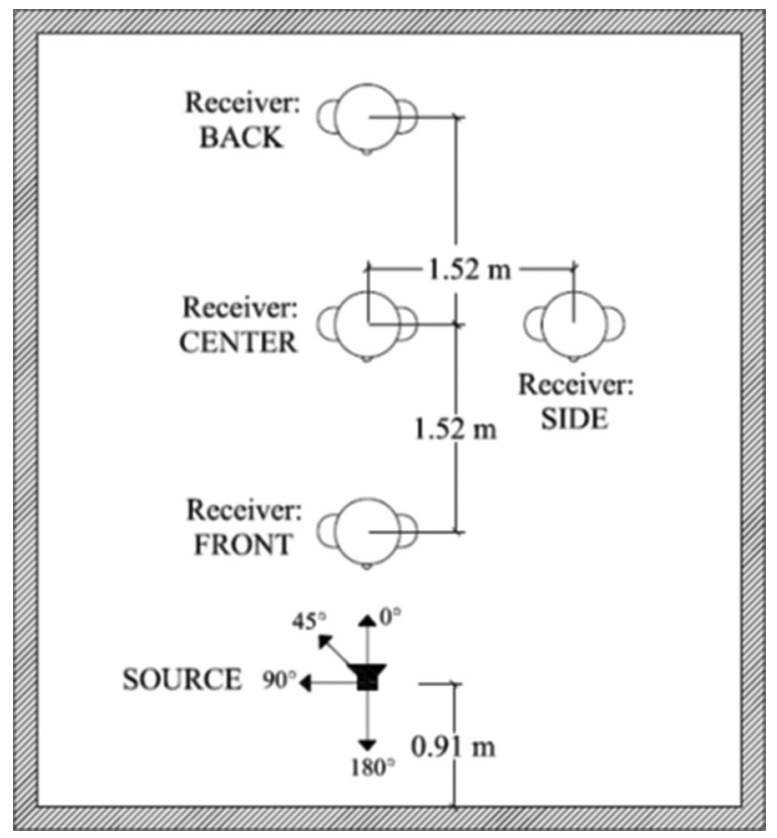

FIG. 1. Plan view of source rotations and receiver positions used for BRIR measurements (not to scale).

measurement, the source was located at the front of the classroom, approximately $0.91 \mathrm{~m}$ from the wall and $1.68 \mathrm{~m}$ above the floor. The four source rotations included $0^{\circ}$ from center, $45^{\circ}$ from center, $90^{\circ}$ from center, and $180^{\circ}$ from center (refer to Fig. 1) to simulate a teacher facing various directions while speaking. The receiver was directly facing the front of the room for each measurement, located in four different positions throughout the room. For the center position, the receiver was located at the approximate center of the room. The receiver was located $1.52 \mathrm{~m}$ to the front, side, and back of the center position for the three other positions. Therefore, the receiver was closer to the source for all of the measurement configurations in classrooms with a shorter distance from the front to the back of the room.

A JBL LSR6325P-1 loudspeaker, with a $134 \mathrm{~mm}(5.25$ in.) diameter low frequency transducer and a $25 \mathrm{~mm}$ (1 in.) diameter high frequency transducer, was used for the source. This loudspeaker was selected because its directivity characteristics are similar to those of a human talker. The level of the loudspeaker while generating pink noise was set to $65 \mathrm{dBA}$ (re: $20 \mu \mathrm{Pa}$ ) at a distance of $1 \mathrm{~m}$ directly in front of the speaker. The signal used for each BRIR measurement was a pinkweighted logarithmic sweep with four averages generated and recorded by the Electronic and Acoustic System Evaluation and Response Analysis (EASERA) computer software program. A G.R.A.S. Sound and Vibration KEMAR Manikin Type 45BA was used for the receiver. The manikin ear height was $1.0 \mathrm{~m}$ above the ground for all of the measurements.

The measurements were repeated three times in 19 classrooms for each configuration to quantify the measurement repeatability. The BRIRs could only be gathered two times for each measurement configuration in one of the classrooms (9C) due to time constraints. The source rotation and receiver manikin were moved between each set of repeated measurements.

\section{F. Standardized achievement tests student demographics}

Students in the third and fifth grade classrooms surveyed remain in the same classroom for the majority of their classroom instruction, so this investigation is interested in how the one classroom's acoustical environment may impact student learning outcomes. Students in the surveyed classrooms completed four different standardized achievement tests during the 2009-2010 academic year. The students typically completed the achievement tests in the classroom spaces surveyed. The average test scores across students in each individual classroom were provided by the school district, rather than averaged per grade level as in the Ronsse and Wang (2010) study.

Terra Nova tests in the math, language, and reading subject areas were administered to the third and fifth-grade students in November 2009. Terra Nova assessment tests are available to schools nation-wide. The math and reading subject scores were reported as normal curve equivalent (NCE) scores, and the language subject scores were reported as percentile rank scores. Another set of tests in the reading subject area developed by the state of NE, called Nebraska State Accountability tests, were administered to the students in March 2010. These results were reported as scale scores.

The percentage of students in each classroom who received free or reduced-price school lunches was also gathered. This demographic variable was used to control for socio-economic differences among the students in some of the data analyses.

\section{RESULTS}

Results from the acoustical measurements, standardized student achievement tests, and student demographic data are presented in this section. The acoustical metrics presented include BNL, RT, and distortion of frequency-smoothed magnitude (DFSM). Several metrics from the BRIR measurements, including STI, DFSM, IACC $E$, and ILD, were compared to the RT, BNL, and achievement scores for the 20 classrooms in which BRIR measurements were conducted. This paper focuses on DFSM only, since STI, IACC $_{E}$, and ILD values were not found to be significantly correlated to student achievement (Ronsse, 2011).

\section{A. Background noise level}

The A-weighted equivalent sound levels $\left(\mathrm{L}_{\mathrm{Aeq}}\right)$ over the 5 min measurement period for both the heating and cooling mechanical system modes in each classroom are shown in Figs. 2 and 3 for the third- and fifth-grade classrooms, respectively. However, in Classrooms 7A, 7B, 7C, and 7D the mechanical system fan motor was not activated during the BNL measurements. This motor would typically be running while the classrooms were occupied, generating different noise levels than those measured with the fan deactivated. The temperature-weighted average $\mathrm{L}_{\text {Aeq }}$ values from August through November 2009 (8/09-11/09) and August 2009 through March 2010 (8/09-3/10) are also shown in these figures. These averages were calculated from the 


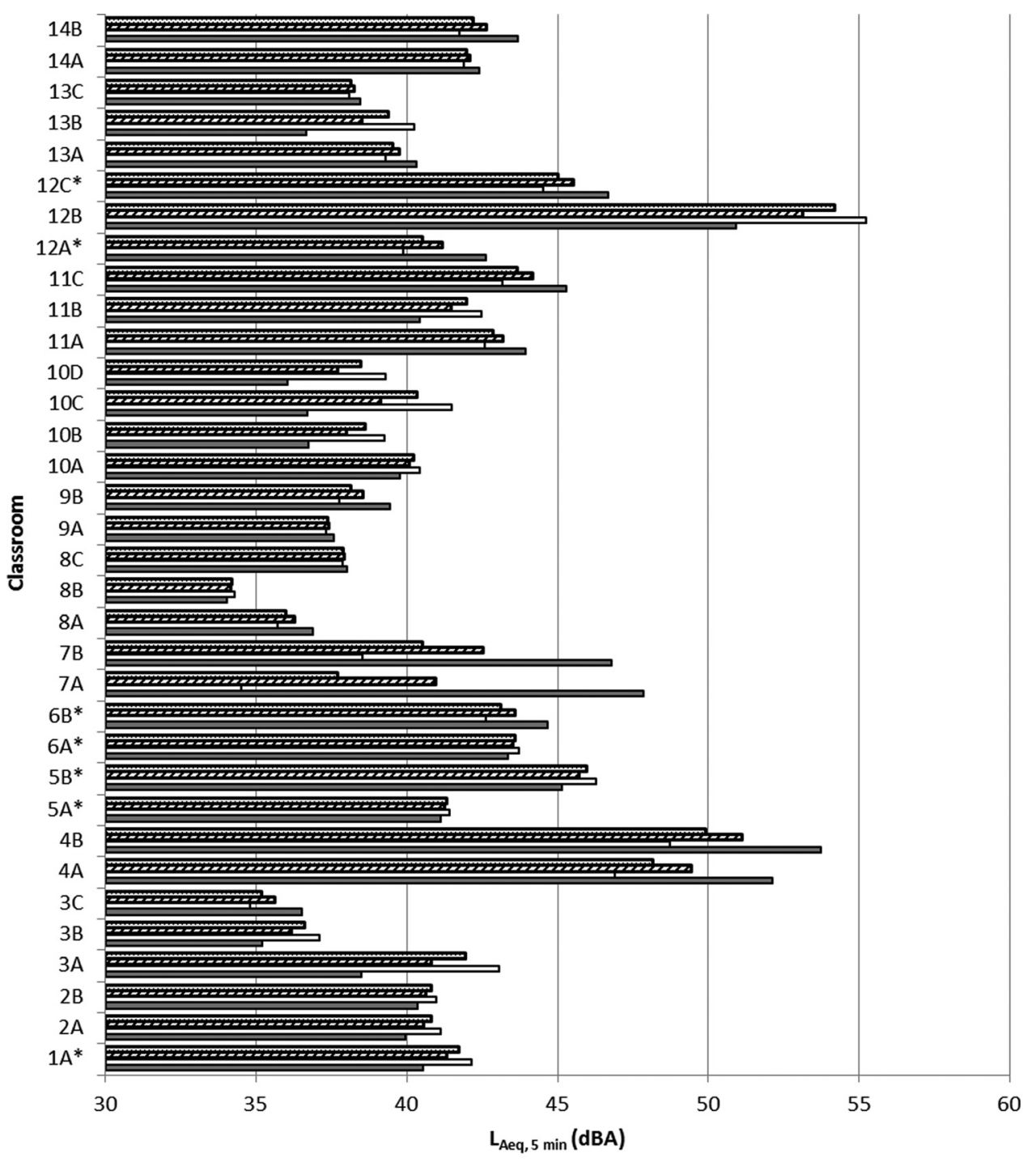

FIG. 2. A-weighted equivalent sound levels for all of the third-grade classrooms. The * denotes open plan, closed plan with open door, and portable classrooms, which were not included in the analyses described in Sec. IV A.

-

percentage of days the mechanical systems were assumed to be operating in the cooling and heating modes based on local weather data while school was in session during these time periods, as shown in Eq. (1),

$$
\mathrm{BNL}_{\mathrm{TWA}}=\mathrm{BNL}_{\mathrm{C}}\left(\frac{\mathrm{N}_{\mathrm{C}}}{\mathrm{N}_{\mathrm{T}}}\right)+\mathrm{BNL}_{\mathrm{H}}\left(\frac{\mathrm{N}_{\mathrm{H}}}{\mathrm{N}_{\mathrm{T}}}\right),
$$

where $\mathrm{BNL}_{\mathrm{TWA}}=$ Temperature-weighted average $\mathrm{BNL}$ over a given time period; $\mathrm{BNL}_{\mathrm{C}}=\mathrm{BNL}$ with classroom mechanical system operating in the cooling mode; $\mathrm{BNL}_{\mathrm{H}}=\mathrm{BNL}$ with classroom mechanical system operating in the heating mode; $\mathrm{N}_{\mathrm{C}}=$ number of days classroom mechanical system is operating in the cooling mode while school is in session over a given time period; $\mathrm{N}_{\mathrm{H}}=$ number of days classroom mechanical system is operating in the heating mode while school is in session over a given time period; and $\mathrm{N}_{\mathrm{T}}=$ total number of days school is in session over a given time period.

In most classrooms, the BNLs in the heating and cooling modes are similar, though large differences occur in some of the spaces. Based on the outdoor air temperatures, the mechanical systems should have been operating in the cooling mode for 33 out of the 68 days school was in session from August to November 2009, and operating in the heating mode for the rest of the days. The mechanical systems should have been operating in the cooling mode for 33 out of the 137 days school was in session from August 2009 to March 2010, and operating in the heating mode for the other 104 days. Since the mechanical systems were operating in the heating mode for most of the school days from August 2009 to March 2010, these temperature-weighted BNL averages are more similar to the heating BNLs.

As shown in Figs. 2 and 3, the $\mathrm{L}_{\mathrm{Aeq}}$ values range from 33 to $54 \mathrm{dBA}$, most of which exceed the BNL recommendations in the ANSI S12.60 Standard (ANSI, 2010). The $\mathrm{C}$-weighted equivalent sound levels $\left(\mathrm{L}_{\mathrm{Ceq}}\right)$ over the $5 \mathrm{~min}$ measurement period for both the heating and cooling mechanical system modes were also examined (Ronsse, 2011). The $\mathrm{L}_{\mathrm{Ceq}}$ values range from 47 to $72 \mathrm{dBC}$, which generally exceed the recommendations in the ANSI S12.60 Standard (ANSI, 2010). However the differences between the $\mathrm{L}_{\text {Aeq }}$ and the $\mathrm{L}_{\mathrm{Ceq}}$ values are only greater than $20 \mathrm{~dB}$ in six of the classrooms, and the largest difference observed is $23 \mathrm{~dB}$. This indicates that the low-frequency noise is not excessively 


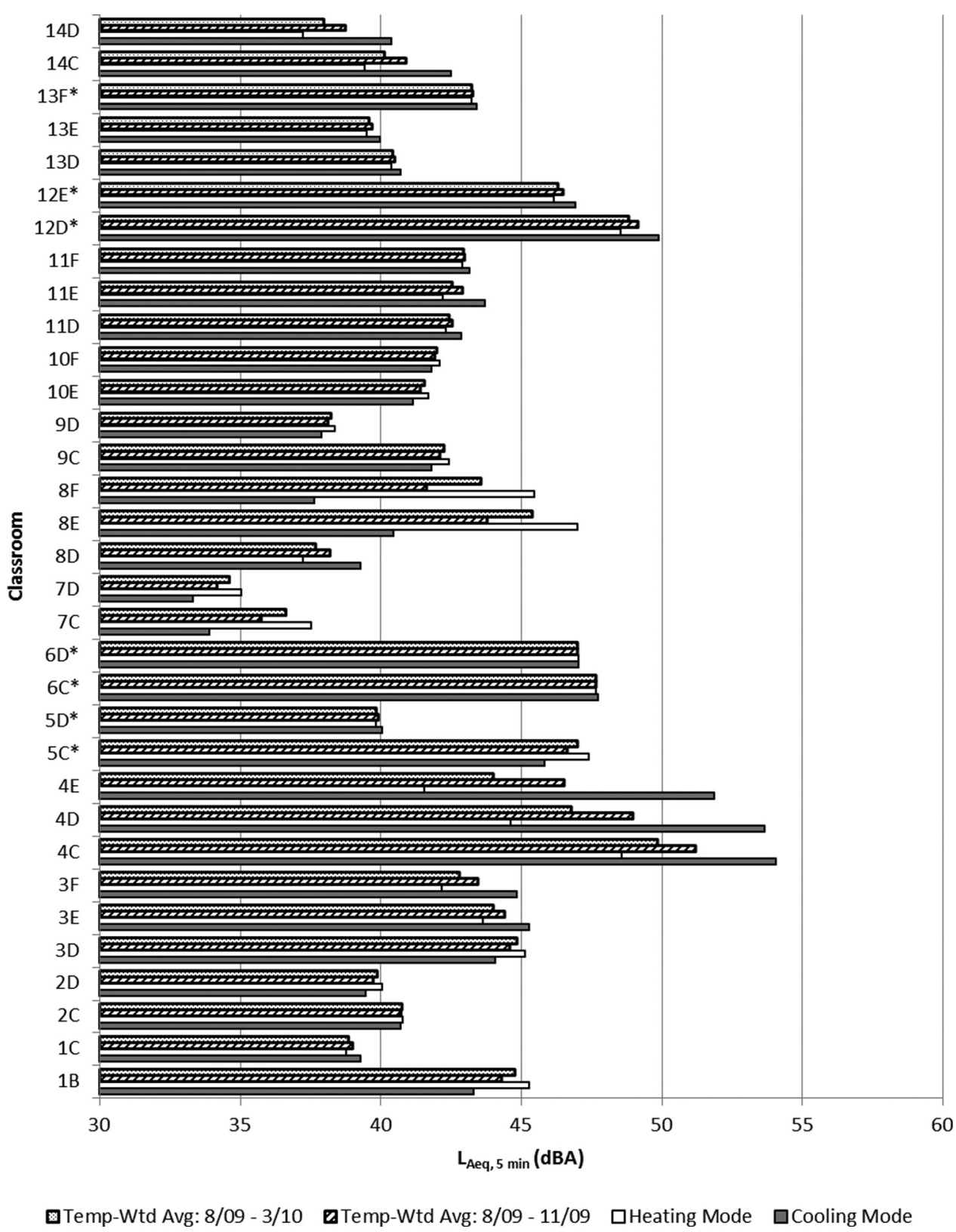

FIG. 3. A-weighted equivalent sound levels for all of the fifth-grade classrooms. The * denotes open plan and closed plan with open door classrooms, which were not included in the analyses described in Sec. IV A.

dominant in most of the classrooms. The unoccupied BNLs referenced in the remainder of the paper are the $\mathrm{L}_{\mathrm{Aeq}}$ values.

\section{B. Reverberation time}

The unoccupied RTs averaged across the 500 and $1000 \mathrm{~Hz}$ octave bands are shown in Figs. 4 and 5 for the third- and fifth-grade classrooms, respectively. The RT shown for all of the classrooms is the estimated $T_{20}$ value from the balloon pop impulse response (IR) measurements. These figures also show the $T_{20}$ values averaged for the left and right ears from the logarithmic sweep IR measurements for 20 of the classrooms. The mid-frequency RT is below $0.6 \mathrm{~s}$ for all of the classrooms, as specified in the ANSI S12.60 Standard (ANSI, 2010).

The RTs calculated from the logarithmic sweep IR measurements are typically within $0.1 \mathrm{~s}$ of the RT values estimated from the balloon pop IR measurements. However, larger differences occur for Classrooms $12 \mathrm{~B}$ and 13D. In these classrooms, the RT calculated from the logarithmic sweep IR measurements is $0.13 \mathrm{~s}$ higher than the RT estimated from the balloon pop IR measurement for Classroom $12 \mathrm{~B}$ and $0.16 \mathrm{~s}$ higher for Classroom 13D. Note that the range of RTs across the classrooms selected for BRIR measurements is still quite narrow, and the values are below the upper RT limit specified in the ANSI S12.60 Standard (ANSI, 2010).

\section{Distortion of frequency-smoothed magnitude}

Although the DFSM values were calculated at 16 source-receiver conditions in each classroom, with the receiver in four different locations and the source in four different rotations, only a typical measurement configuration (center receiver position, $0^{\circ}$ source rotation) and one additional measurement configuration (back receiver position, 


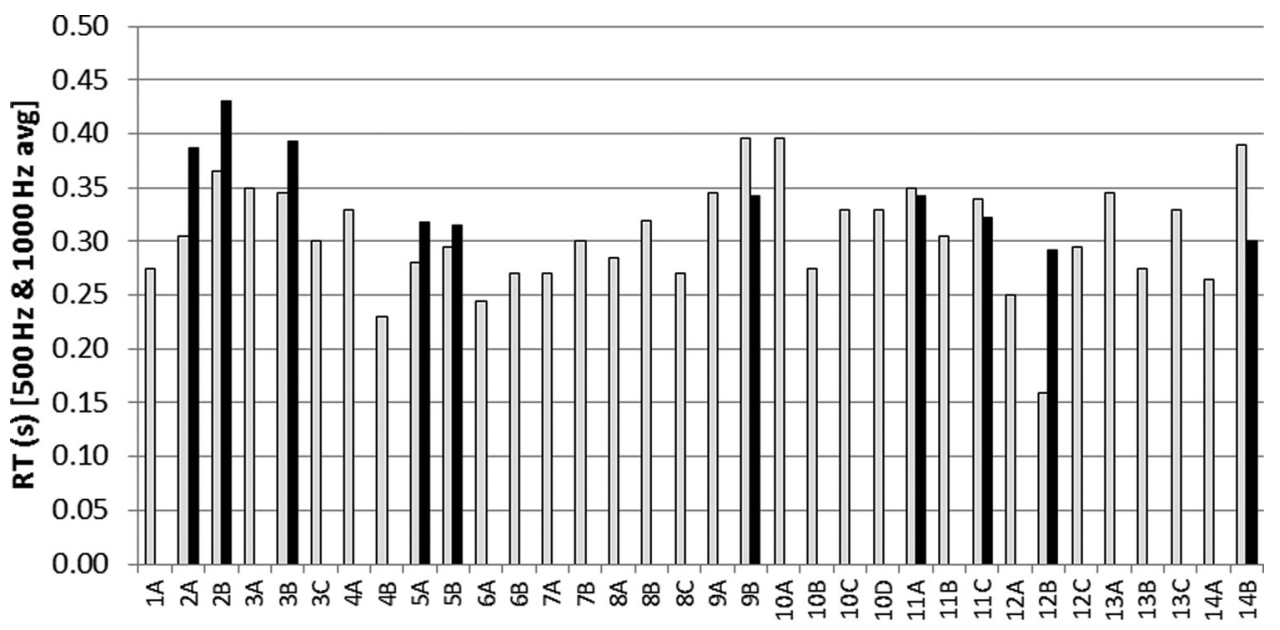

FIG. 4. RT average in the 500 and $1000 \mathrm{~Hz}$ octave bands for the thirdgrade classrooms.

Classroom

$\square$ Balloon Pop IR

Logarithmic Sweep IR

$90^{\circ}$ source rotation) are shown for all classrooms. The variation of these metrics within Classroom 11A is also presented.

Figure 6 shows the left and right ear DFSM values for the center receiver position, $0^{\circ}$ source rotation for the 20 BRIR classrooms. The DFSM values among classrooms in this condition range from 3 to $7 \mathrm{~dB}$ (re: Anechoic), and the DFSM values measured in the left and right ear are similar within each classroom.

The left and right ear DFSM values for the back receiver position, $90^{\circ}$ source rotation are shown in Fig. 7. A wider range of DFSM values occurs for this condition, ranging from 8 to $18 \mathrm{~dB}$ (re: Anechoic). The right ear DFSM values are typically greater than the left ear DFSM values in this measurement configuration, as might be expected since more direct early reflections are reaching the right ear than the left ear. The lowest DFSM values occur in Classrooms 12B and $13 \mathrm{E}$, which have mid-frequency reverberation times of $0.30 \mathrm{~s}$ and $0.36 \mathrm{~s}$, respectively, and are two of the rooms with the shortest distances from source to receivers. Therefore, less spectral distortion of the signal may occur in cases with short paths from the talker to the listener. Classroom $3 \mathrm{~B}$ is the only space with a shorter distance from the source to the receiver for all conditions than Classrooms 12B and 13E.

The DFSM values measured at the left ear in Classroom 11A are shown in Fig. 8. The DFSM values generally tend to increase as the receiver moves from the front to the center to the side to the back position, though this varies with source rotation. The DFSM values are typically smallest for the $0^{\circ}$ source rotation and largest for the $90^{\circ}$ source rotation. The $0^{\circ}$ source rotation has a shorter source-to-receiver path than the $90^{\circ}$ source rotation, which may be why less spectral distortion is occurring for the $0^{\circ}$ source rotation. The DFSM trends occurring for the right ear are similar to those occurring for the left ear, though the magnitude of the values is generally slightly higher.

These results indicate that classrooms or measurement configurations with shorter paths from the source to the receiver and source rotations directly facing the receiver generally have lower DFSM values.

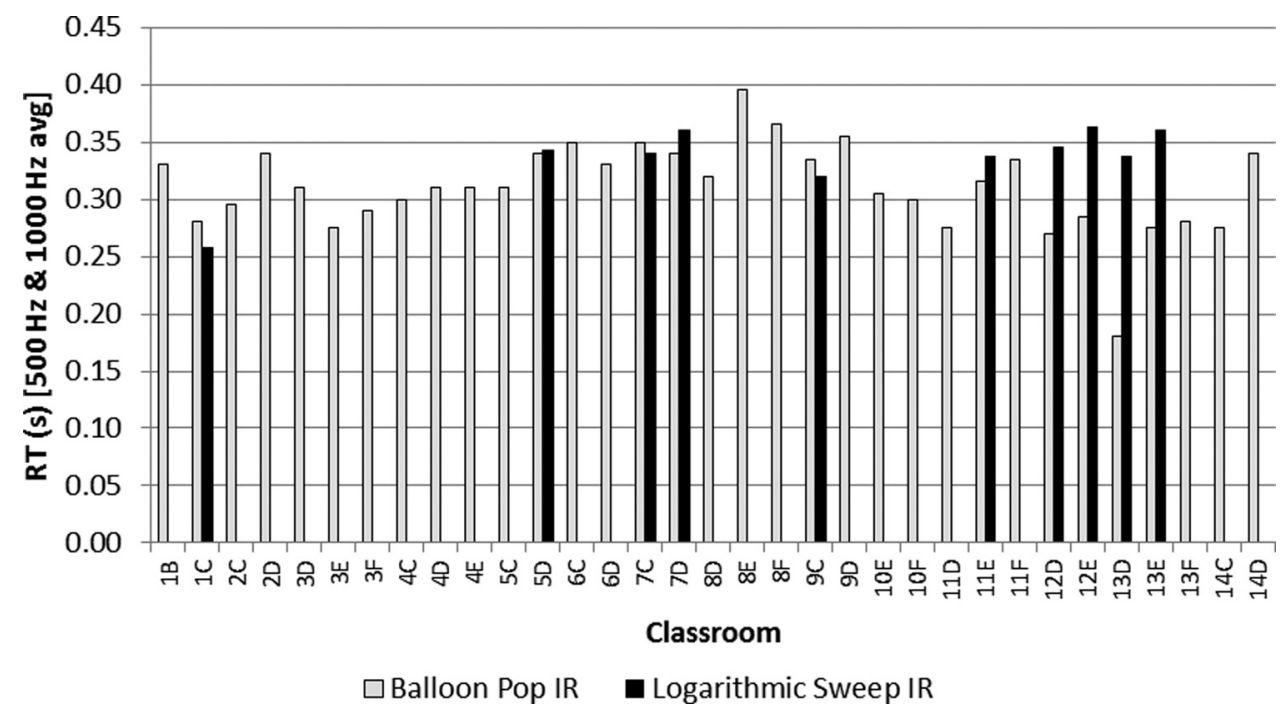

FIG. 5. RT average in the 500 and $1000 \mathrm{~Hz}$ octave bands for the fifthgrade classrooms. 


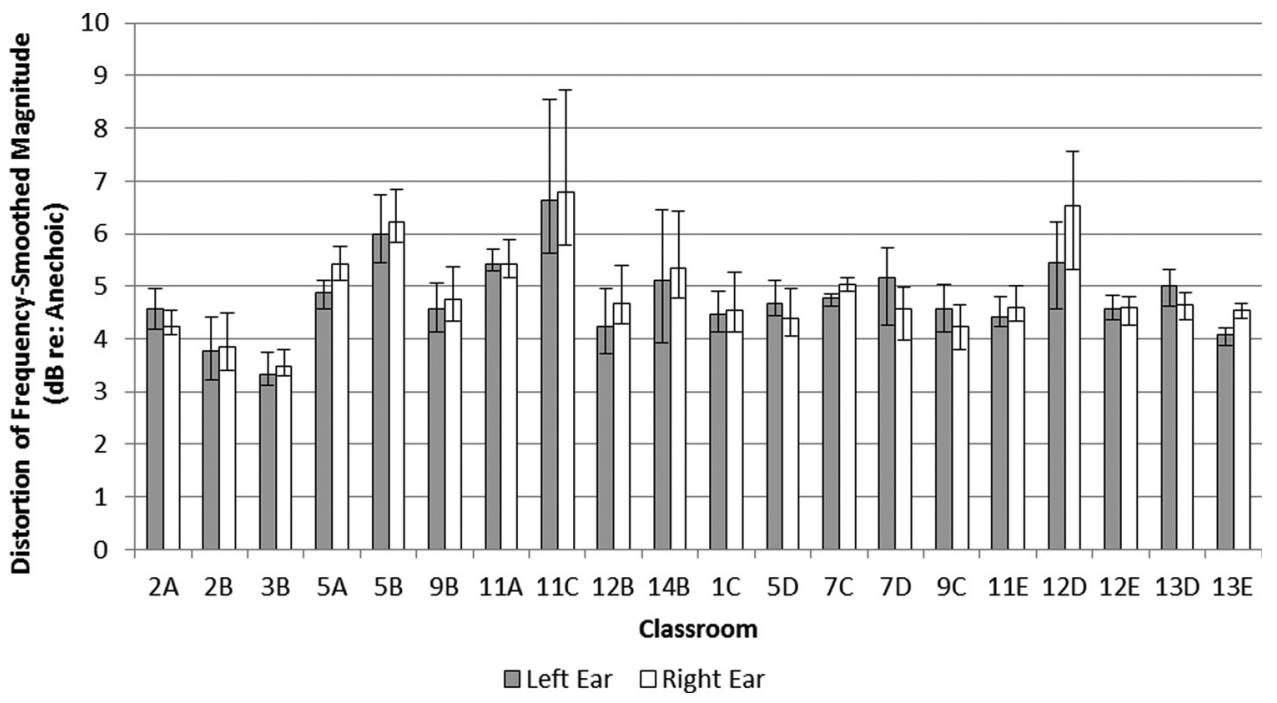

FIG. 6. Distortion of frequencysmoothed magnitude values for the center receiver position, $0^{\circ}$ source rotation. Error bars show the range about the average value from the three sets of repeated measurements.

\section{Standardized achievement tests and student demographics}

The results from the standardized achievement tests and the free and reduced-price lunches are shown in Tables I and II for the third and fifth-grade classrooms, respectively. The state of NE also set the relationship between the Nebraska State Accountability reading test scores and the target performance level for the third and fifth-grade students for the 2009-2010 academic year, as shown in Table III.

\section{DATA ANALYSES AND DISCUSSION}

Statistical analyses relating the classroom acoustical metrics to the standardized achievement scores have been conducted for the surveyed classrooms. The statistical tests indicate which metrics are highly correlated to student achievement. To determine if parametric statistical tests should be used, the distributions of the acoustical metrics, standardized achievement scores, and student demographic data from all of the classrooms surveyed were tested for normality. Results from the Kolmogorov-Smirnov tests for normality indicate that neither the achievement score nor demographic data distributions significantly deviate from normal distributions (Field, 2000). Therefore, parametric statistical tests, including Pearson correlations, may be used to analyze these variables. However, some of the distributions of the acoustics metrics for the data sets considered significantly deviate from normality. Thus Spearman correlations are used to analyze these variables, as noted on the correlation tables for each data set.

Zero-order Pearson correlations between the student achievement scores and percent of students receiving free or reduced-price lunches in each classroom were conducted. Significant negative correlations occur between all of the achievement test scores and the percentage of students receiving free or reduced-price lunches $(p<0.01)$. This indicates that classrooms containing a larger percentage of students receiving free or reduced-price lunches also had students with lower achievement scores, in line with previous findings (Okpala et al., 2001). Because a significant relationship occurs between achievement scores and free or reduced-price lunches, this demographic variable was used as a control variable for some of the statistical analyses.

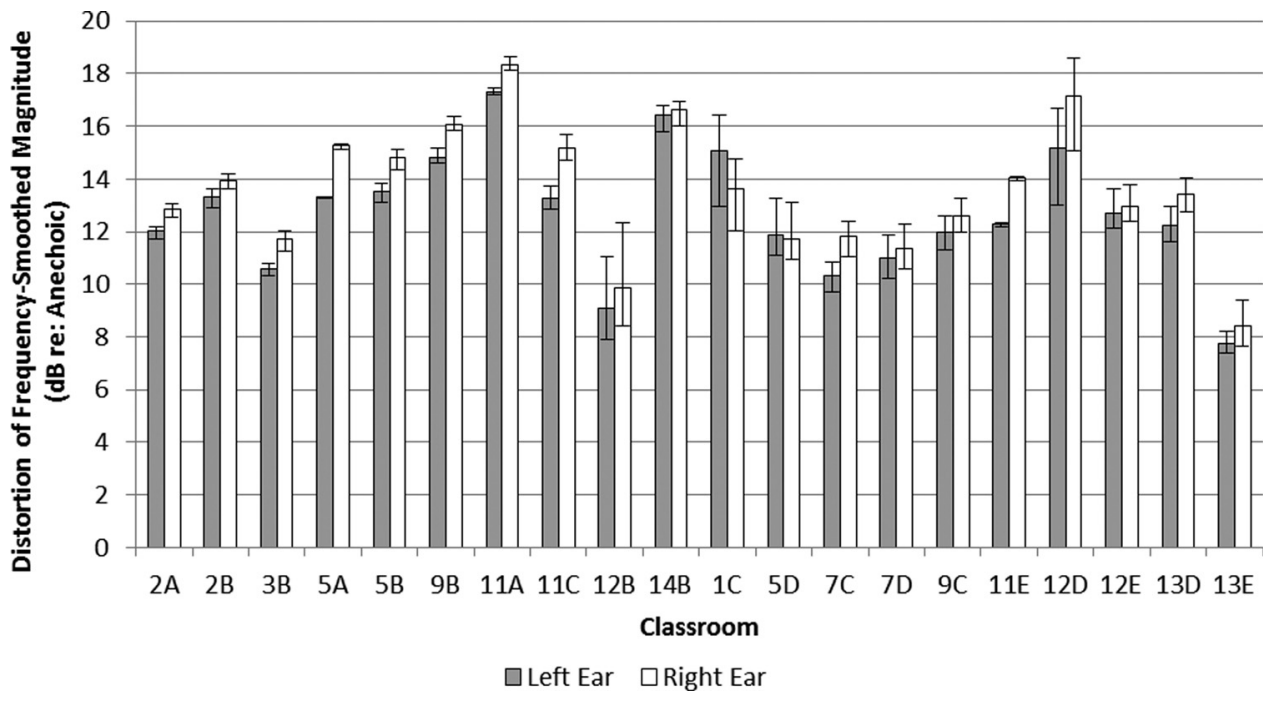

FIG. 7. Distortion of frequencysmoothed magnitude values for the back receiver position, $90^{\circ}$ source rotation. Error bars show the range about the average value from the three sets of repeated measurements. 


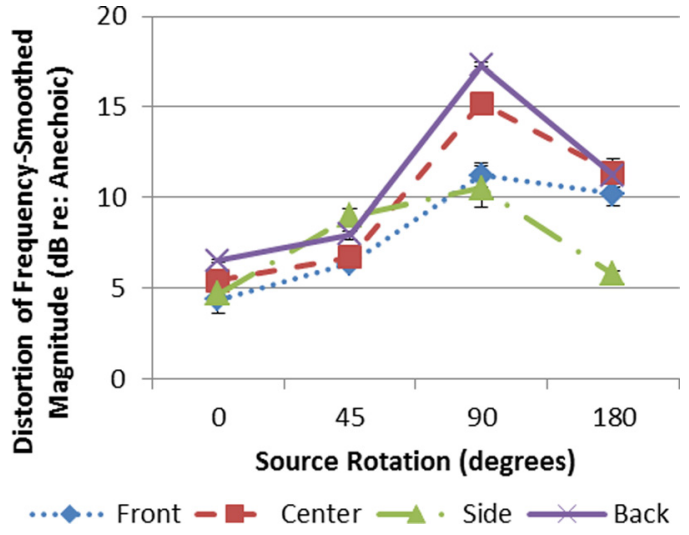

FIG. 8. (Color online) Distortion of frequency-smoothed magnitude values measured at the left ear in Classroom 11A. Error bars show the range about the average value from the three sets of repeated measurements.

\section{A. Background noise level versus achievement}

The classroom BNLs were compared to the average student achievement scores per classroom. Since the mechanical system fan motor was deactivated in the school containing Classrooms 7A, 7B, 7C, and 7D, these classrooms were omitted from the BNL analyses. Also, intrusive noise causes higher occupied noise levels in open-plan classrooms than closed-plan classrooms, due to the lack of isolation from noise in the hallways and adjacent rooms for open-plan classrooms (Shield et al., 2010). Therefore, data analyses were conducted with the open plan, open door, and portable classrooms removed from the data sets, leaving 25 third-grade and 24 fifth-grade classrooms in the subsequent BNL analysis.

The Pearson or Spearman correlations relating BNL to the achievement scores were calculated for the third-grade and fifth-grade classrooms. All correlations between BNL and the third-grade student achievement scores for the classrooms with closed-plans and consistent HVAC conditions are non-significant $(p>0.05)$. The correlations between BNL and the achievement test scores for the closed-plan fifth-grade classrooms with consistent HVAC conditions are shown in Table IV. The BNL variables shown are the $\mathrm{L}_{\text {Aeq }}$ values measured with the mechanical system operating in the cooling mode $\left(\mathrm{BNL}_{\mathrm{C}}\right)$, in the heating mode $\left(\mathrm{BNL}_{\mathrm{H}}\right)$, and the average noise levels calculated based on weather data from

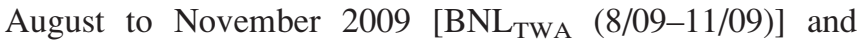
from August 2009 to March 2010 [BNL TWA $(8 / 09-3 / 10)]$.

TABLE III. Nebraska State Accountability reading test scores and target student performance levels.

\begin{tabular}{lcc}
\hline \hline Grade Level & Scale Score & Performance Level \\
\hline Third & $135-200$ & Exceeds Target \\
& $85-127$ & Meets Target \\
& $1-81$ & Below Target \\
Fifth & $141-200$ & Exceeds Target \\
& $85-133$ & Meets Target \\
& $1-80$ & Below Target \\
\hline \hline
\end{tabular}

The correlation coefficients between the BNL variables (1-4) and the achievement test score variables (5-8) reflect the relationships between BNL and student achievement.

The cooling BNL is significantly negatively correlated to the State Accountability reading test score $(r=-0.41$, $p<0.05)$. Also, a significant negative correlation exists between the Terra Nova language test score and the temperature-weighted average BNL from August 2009 to November $2009(r=-0.51, p<0.05)$. Since the students completed the Terra Nova tests in November 2009, this BNL average should reflect the cumulative noise levels the students experienced prior to taking this test.

The State Accountability reading test score is significantly negatively correlated to the temperature-weighted average BNL from August 2009 to November $2009(r=-0.44, p<0.05)$, but it is not significantly correlated to the temperature-weighted BNL average from August 2009 to March 2010. The relationship between the State Accountability reading test score and the temperature-weighted average BNL from August 2009 to November 2009 will not be further investigated, since the students took the State Accountability reading test in March 2010.

When controlling for the effects of free or reduced-price lunches on achievement, though, none of the semi-partial correlations between BNL and the achievement test scores are statistically significant. This means that when the effects of free or reduced-price lunches are factored out of the achievement scores, the amount of new variance in achievement accounted for by BNL is non-significant (Field, 2000). Shield and Dockrell (2008) also did not find significant correlations between unoccupied classroom BNL and student achievement when correcting for effects of student demographics. In the Ronsse and Wang (2010) study, however, the correlations between student reading comprehension and unoccupied BNL were significant even when controlling for the effects of poverty rates on achievement.

The scatter plots between BNL and the achievement test scores with significant correlations are shown in Figs. 9 and 10. The scatter plot between the temperature-weighted average BNL from August 2009 to November 2009 and the Terra Nova language test scores is shown in Fig. 9. The regression model for the linear relationship plotted in this figure is given in Eq. (2),

$$
\mathrm{LS}=125.89-\left(1.49 \times \mathrm{BNL}_{\mathrm{TWA}}\right),
$$

where $\mathrm{LS}=$ Fifth-grade Terra Nova language test score and $\mathrm{BNL}_{\mathrm{TWA}}=$ Temperature-weighted average BNL from $\mathrm{Au}$ gust to November 2009.

The regression model with the temperature-weighted average $\mathrm{BNL}$ as the predictor variable is significant at the 0.05 level $[F(1,22)=7.57, p<0.05]$, with BNL accounting for $26 \%$ of the variance in the Terra Nova language scores $\left(R^{2}=0.26, p<0.05\right)$.

Figure 10 contains the scatter plot between the cooling BNL and the State Accountability reading scores. The model for the regression line plotted in this figure is given in Eq. (3),

$$
\mathrm{RS}=170.95-\left(1.38 \times \mathrm{BNL}_{\mathrm{C}}\right)
$$


TABLE IV. Correlations between BNL and fifth-grade student achievement scores for the closed-plan classrooms with consistent HVAC conditions. ${ }^{\text {a }}$

\begin{tabular}{|c|c|c|c|c|c|c|c|c|}
\hline Variable & 1 & 2 & 3 & 4 & 5 & 6 & 7 & 8 \\
\hline 1. $\mathrm{BNL}_{\mathrm{C}}$ & - & $0.55 * *(\mathrm{~s})^{\mathrm{b}}$ & $0.85 * *(\mathrm{~s})$ & $0.70 * *(\mathrm{~s})$ & $-0.19(\mathrm{~s})$ & $-0.39(\mathrm{~s})$ & $-0.36(\mathrm{~s})$ & $-0.41 *(\mathrm{~s})$ \\
\hline 2. $\mathrm{BNL}_{\mathrm{H}}$ & - & - & $0.85^{* *}(\mathrm{p})^{\mathrm{c}}$ & $0.96^{* *}(\mathrm{p})$ & $-0.09(\mathrm{p})$ & $-0.22(\mathrm{p})$ & $-0.14(\mathrm{p})$ & $-0.30(\mathrm{p})$ \\
\hline 3. $\mathrm{BNL}_{\mathrm{TWA}}(8 / 09-11 / 09)$ & - & - & - & $0.96^{* *}(\mathrm{p})$ & $-0.27(\mathrm{p})$ & $-0.51 *(\mathrm{p})$ & $-0.36(\mathrm{p})$ & $-0.44 *(\mathrm{p})$ \\
\hline 4. $\mathrm{BNL}_{\mathrm{TWA}}(8 / 09-3 / 10)$ & - & - & - & - & $-0.18(\mathrm{p})$ & $-0.37(\mathrm{p})$ & $-0.25(\mathrm{p})$ & $-0.37(\mathrm{p})$ \\
\hline 5. Terra Nova Math & - & - & - & - & - & $0.73^{* *}(\mathrm{p})$ & $0.83 * *(\mathrm{p})$ & $0.79 * *(\mathrm{p})$ \\
\hline 6. Terra Nova Language & - & - & - & - & - & - & $0.85 * *(\mathrm{p})$ & $0.80 * *(\mathrm{p})$ \\
\hline 7. Terra Nova Reading & - & - & - & - & - & - & - & $0.91 * *(\mathrm{p})$ \\
\hline 8. State Reading & - & - & - & - & - & - & - & - \\
\hline
\end{tabular}

${ }^{\mathrm{a}} \mathrm{N}=24 ; * \mathrm{p}<0.05 ; * * \mathrm{p}<0.01$.

$\mathrm{b}(\mathrm{s})$ : Spearman Correlation.

${ }^{\mathrm{c}}(\mathrm{p})$ : Pearson Correlation.

where $\mathrm{RS}=$ Fifth-grade State Accountability reading test score and $\mathrm{BNL}_{\mathrm{C}}=$ Cooling $\mathrm{BNL}$.

This model is significant at the 0.05 level $[F(1,22)$ $=5.91, p<0.05]$, with the cooling BNL accounting for $21 \%$ of the variance in the State Accountability reading scores $\left(R^{2}=0.21, p<0.05\right)$. The unoccupied cooling BNLs corresponding to the State Accountability reading scores for different student performance levels predicted by this regression model are shown in Table $\mathrm{V}$. As shown in this table, a cooling BNL of $45 \mathrm{dBA}$ corresponds to the average State Accountability reading score that meets the upper target performance level. However, the cooling BNL decreases to $22 \mathrm{dBA}$ for a reading score that exceeds the target level.

The regression model with both the cooling BNL and the percent of students receiving free or reduced-price lunches as predictor variables for the State Accountability reading scores is given in Eq. (4),

$$
\mathrm{RS}=131.51-\left(0.20 \times \mathrm{BNL}_{\mathrm{C}}\right)-(0.63 \times \mathrm{FRL}),
$$

where $\mathrm{RS}=$ Fifth-grade State Accountability reading test score; $\mathrm{BNL}_{\mathrm{C}}=$ Cooling $\mathrm{BNL}$; and $\mathrm{FRL}=$ Percentage of students receiving free or reduced-price lunches.

This model is significant at the 0.01 level $[F(2,21)$ $=11.40, p<0.01]$, with $52 \%$ of the variance in the reading scores accounted for by the predictor variables $\left(R^{2}=0.52, p<0.01\right)$. However, the significant predictor variable is free or reduced-price lunches $[t(21)=-3.68$, $p<0.01]$, rather than the cooling BNL $[t(21)=-0.36$, $p>0.05]$.

\section{B. Reverberation time versus achievement}

The average RT in the $500 \mathrm{~Hz}$ and $1000 \mathrm{~Hz}$ octave from the balloon pop impulse response measurements shown in Figs. 4 and 5 in all of the classrooms was compared to the student achievement test scores averaged per classroom. None of the distributions compared significantly deviate from normality; therefore, Pearson correlations were used for the analyses. All of the correlations between RT and achievement are non-significant at the 0.05 level, indicating the classroom RTs within the range included in this study do not impact student achievement.

\section{Distortion of frequency-smoothed magnitude versus achievement}

Because the achievement test results are averaged among all of the students in each classroom, the DFSM was averaged among all of the receiver positions in each classroom as well. The average results from the $0^{\circ}$ source rotation measurement configuration per classroom are examined, since it is expected that the teacher would typically project his/her voice towards the classroom while speaking. The mid-frequency RTs included in this section's analysis are calculated from the logarithmic sweep impulse responses, as shown in Figs. 4 and 5.

The Pearson or Spearman correlations between the following acoustics metrics from the 20 classrooms in which BRIR measurements were conducted are shown in Table VI: (1) $\mathrm{L}_{\text {Aeq }}$ with the mechanical system operating in the cooling mode $\left(\mathrm{BNL}_{\mathrm{C}}\right)$, (2) $\mathrm{L}_{\mathrm{Aeq}}$ with the mechanical system operating in the heating mode $\left(\mathrm{BNL}_{\mathrm{H}}\right)$, (3) average RT across 500 and $1000 \mathrm{~Hz}$ octave bands $\left(\mathrm{RT}_{\text {mid }}\right)$, (4) DFSM measured at the left ear $\left(\mathrm{DFSM}_{\mathrm{L}}\right)$, (5) DFSM measured at the right ear $\left(\mathrm{DFSM}_{\mathrm{R}}\right)$, and (6) difference between the left and right ear DFSM values $\left(\right.$ DFSM $\left._{|L-R|}\right)$.

Significant negative correlations exist between the midfrequency RT and the DFSM left ear values $(r=-0.50$, $p<0.05)$ and right ear values $(r=-0.47, p<0.05)$.

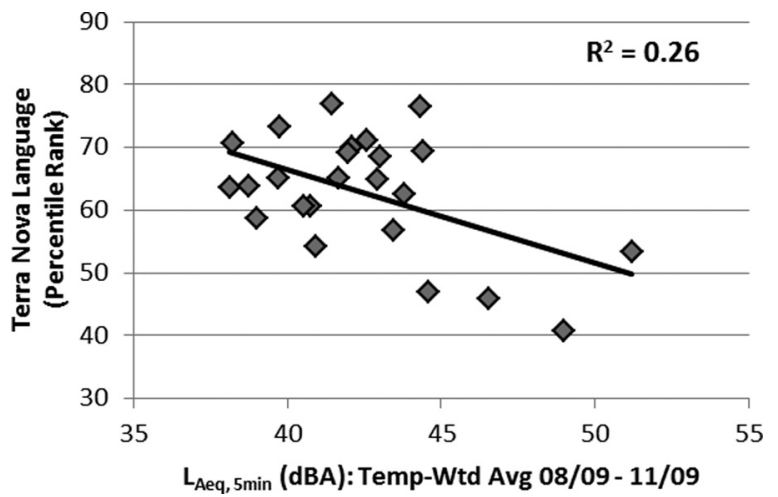

FIG. 9. Scatterplot and linear regression line between temperature-weighted average BNL from August to November 2009 and Terra Nova language test scores for closed-plan fifth-grade classrooms with consistent HVAC conditions. 


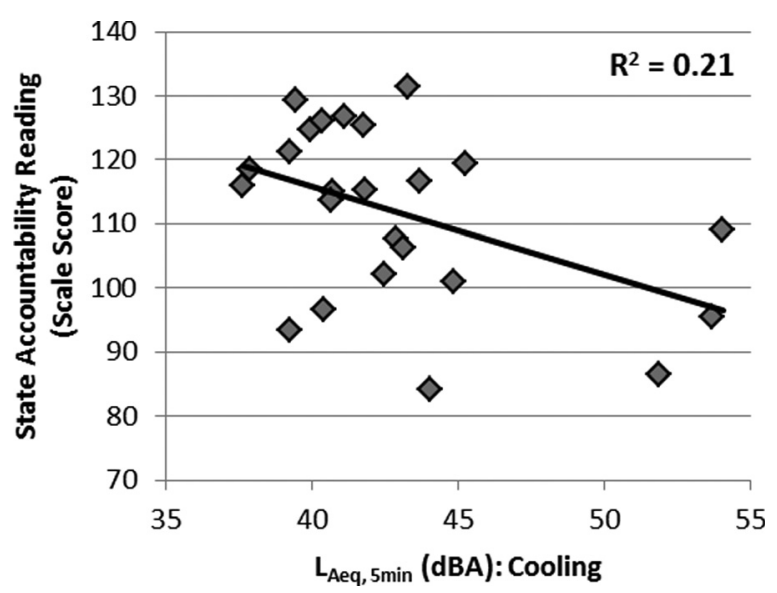

FIG. 10. Scatter plot and linear regression line between cooling mode BNL and State Accountability reading test scores for closed-plan fifth-grade classrooms with consistent HVAC conditions.

Therefore lower DFSM values are occurring in rooms with longer RTs, as expected. The room-averaged DFSM values amongst these 20 classrooms range from 4.0 to $6.1 \mathrm{~dB}$ (re: Anechoic) for the left ear and from 3.9 to $6.4 \mathrm{~dB}$ (re: Anechoic) for the right ear, while the difference between the left ear and right ear DFSM values ranges from 0 to $0.8 \mathrm{~dB}$ (re: Anechoic).

Zero-order Pearson correlations between the DFSM values and the achievement scores were also calculated. These results are shown in Table VII. A significant negative correlation exists between the left ear DFSM and the Terra Nova language test scores $(r=-0.48, p<0.05)$. The relationship between the left ear DFSM and Terra Nova language scores is also significant when controlling for the effects of free or reduced-price lunches on the language scores with a semipartial correlation value of $-0.51[t(17)=-2.45, p<0.05]$. Though the zero-order correlation between the right ear DFSM and Terra Nova language scores is not statistically significant, these variables are significantly correlated when controlling for the effects of free or reduced-price lunches on the language scores. The semi-partial correlation value for this relationship is $-0.46[t(17)=-2.15, p<0.05]$.

The scatter plot between the Terra Nova language scores and the left ear DFSM values is shown in Fig. 11. A similar trend occurs for the right ear. Lower language test scores tend to occur in classrooms with higher DFSM values. Because DFSM is significantly negatively correlated to RT, it is possible that very low room reverberation has some

TABLE V. Cooling BNLs corresponding to fifth-grade Nebraska State Accountability reading test scores and student performance levels predicted by Eq. (3) from regression model calculated with closed-plan classrooms with consistent HVAC conditions.

\begin{tabular}{lcc}
\hline \hline $\begin{array}{l}\text { Student } \\
\text { Performance Level }\end{array}$ & $\begin{array}{c}\text { State Accountability } \\
\text { Reading Test (Scale Score) }\end{array}$ & $\begin{array}{c}\mathrm{L}_{\text {Aeq, 5min }}(\mathrm{dBA}): \\
\text { Cooling }\end{array}$ \\
\hline Below Target & 80 & 66 \\
Meets Target & 85 & 62 \\
Meets Target & 109 & 45 \\
Meets Target & 133 & 28 \\
Exceeds Target & 141 & 22 \\
\hline \hline
\end{tabular}

TABLE VI. Correlations between acoustical metrics for classrooms in which BRIR measurements were conducted. ${ }^{\text {a }}$

\begin{tabular}{lcccccc}
\hline \hline Variable & 1 & 2 & 3 & 4 & 5 & 6 \\
\hline $1 . \mathrm{BNL}_{\mathrm{C}}$ & - & $0.97 * *(\mathrm{~s})^{\mathrm{b}}$ & $-0.31(\mathrm{p})^{\mathrm{c}}$ & $0.41(\mathrm{p})$ & $0.52^{*}(\mathrm{p})$ & $0.02(\mathrm{p})$ \\
$2 . \mathrm{BNL}_{\mathrm{H}}$ & - & - & $-0.32(\mathrm{~s})$ & $0.48^{*}(\mathrm{~s})$ & $0.44(\mathrm{~s})$ & $-0.15(\mathrm{~s})$ \\
3. $\mathrm{RT}_{\mathrm{mid}}$ & - & - & - & $-0.50 *(\mathrm{p})$ & $-0.47 *(\mathrm{p})$ & $0.08(\mathrm{p})$ \\
4. $\mathrm{DFSM}_{\mathrm{L}}$ & - & - & - & - & $0.85^{* *}(\mathrm{p})$ & $0.16(\mathrm{p})$ \\
$5 . \mathrm{DFSM}_{\mathrm{R}}$ & - & - & - & - & - & $0.02(\mathrm{p})$ \\
6. $\mathrm{DFSM}_{\mid \mathrm{L}-\mathrm{Rl}}$ & - & - & - & - & - & - \\
\hline \hline
\end{tabular}

${ }^{\mathrm{a}} \mathrm{N}=20 ; * \mathrm{p}<0.05 ; * * \mathrm{p}<0.01$

$\mathrm{b}(\mathrm{s})$ : Spearman Correlation.

c(p): Pearson Correlation.

impact on the language scores. Alternatively, this may support the theory discussed in Shinn-Cunningham et al. (2005) that localization bias may be occurring in room conditions with higher DFSM values. Localization ability may be particularly advantageous for developing language aptitude in group learning environments, wherein accurate source localization may help the listener focus attention on the teacher in the presence of competing noise sources. The difference between the left and right ear DFSM values and the achievement scores were not significantly related.

\section{Discussion}

The unoccupied RT, BNL, and DFSM in the third and fifth-grade classrooms have been compared to student scores on the Terra Nova math, language, and reading and Nebraska State Accountability reading tests. None of the BNL conditions are significantly correlated to the thirdgrade student achievement scores. Additionally, BNL is not significantly correlated to the fifth-grade Terra Nova math test scores. However, significant negative correlations occur between the cooling BNL and the State Accountability reading scores for the closed-plan fifth-grade classrooms with consistent HVAC conditions. Also, a significant negative correlation exists between the temperature-weighted BNL average from August 2009 to November 2009 and the fifthgrade Terra Nova language test scores. These results indicate that high unoccupied BNLs negatively impact learning processes for the language and reading subject areas for fifthgrade students, but not for the third-grade students.

The differences between how the younger and older students were impacted by BNL may be attributed to possible differences in instructional styles used between the two grade levels. It is possible that more interactive, visual teaching methods were used for the third-graders, causing their learning to be less impacted by noise distractions. However, an examination of teaching styles was not included in the scope of this study. Therefore, this theory has not been validated.

The BNLs measured with the HVAC systems operating in the heating mode are not significantly correlated to the achievement test results. The mechanical systems may have been generating noise similar to the cooling mode conditions more often than the heating mode conditions. However, the 
TABLE VII. Correlations between DFSM and student achievement scores for classrooms in which BRIR measurements were conducted. ${ }^{\mathrm{a}}$

\begin{tabular}{lccr}
\hline \hline Variable & Terra Nova Math & Terra Nova Language & Terra Nova Reading \\
\hline DFSM $_{\mathrm{L}}$ & $-0.36(\mathrm{p})^{\mathrm{b}}$ & $-0.48^{*}(\mathrm{p})$ & $-0.11(\mathrm{p})$ \\
$\operatorname{DFSM}_{\mathrm{R}}$ & $-0.32(\mathrm{p})$ & $-0.44(\mathrm{p})$ & $-0.02(\mathrm{p})$ \\
$\operatorname{DFSM}_{|\mathrm{L}-\mathrm{R}|}$ & $-0.27(\mathrm{p})$ & $0.09(\mathrm{p})$ & $-0.11(\mathrm{p})$ \\
\hline \hline
\end{tabular}

${ }^{\mathrm{a}} \mathrm{N}=20 ; * \mathrm{p}<0.05 ; * * \mathrm{p}<0.01$

$\mathrm{b}(\mathrm{p})$ : Pearson Correlation.

systems were set to operate in the heating mode if the outdoor air temperature was below $12.8^{\circ} \mathrm{C}\left(55^{\circ} \mathrm{F}\right)$, as it was for the majority of the academic year.

The results from the regression analyses indicate that the allowable unoccupied cooling mode BNL for fifth-grade students to perform in the upper half of the range to meet the NE state target levels for reading achievement ranges from 28 to $45 \mathrm{dBA}$. Though this is a wide range of possible acceptable BNLs, the State Accountability reading scores were predicted to improve as the unoccupied BNL was reduced. In an Iowa school district, Ronsse and Wang (2010) previously found that a target BNL of $41 \mathrm{dBA}$ met the state targets for student achievement in reading comprehension, which is within the range of suitable BNLs found for NE.

The measured mid-frequency RTs are not significantly correlated to any of the student achievement test results. As with another study conducted in midwestern elementary school classrooms (Ronsse and Wang, 2010), all of the RTs measured in the Papillion-La Vista School District meet the requirements specified in the ANSI S12.60 Standard (ANSI, 2010). To determine the relationship between RT and achievement, measurements in classrooms with a wider range of RT are needed. The DFSM has been found, however, to be significantly negatively correlated to midfrequency RT, and a significant negative correlation exists between DFSM and the Terra Nova language scores. This suggests that DFSM may discriminate the reverberant characteristics of rooms better than RT, as DFSM provides an indication of the relationship between source localization difficulty and student achievement.

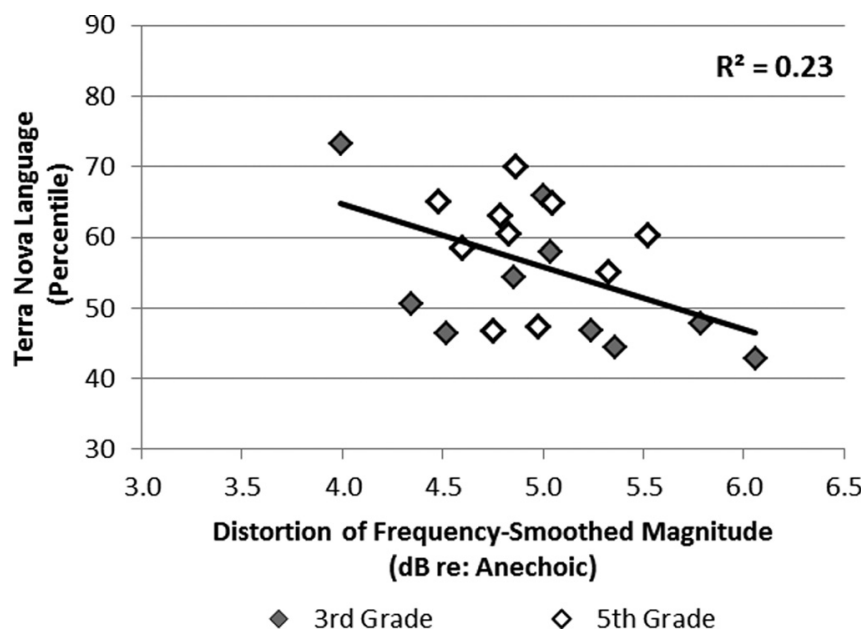

FIG. 11. Scatter plot between left ear distortion of frequency-smoothed magnitude values and Terra Nova language test scores.

\section{CONCLUSIONS}

Investigations of unoccupied classroom acoustical conditions were conducted in an elementary school system in eastern NE, USA. Acoustical metrics in these classrooms, including unoccupied BNL, RT, and DFSM, were correlated to standardized student achievement test results, available in the math, language, and reading subject areas as averages across all students in each classroom. The BNLs compared to the student achievement scores were A-weighted equivalent sound levels $\left(\mathrm{L}_{\mathrm{Aeq}}\right)$ recorded over a 5 min time period, obtained with the mechanical systems operating in both the heating and cooling modes of classrooms with closed floor plan design. Because the mechanical systems were set to operate in either the heating or cooling mode depending on the outdoor air temperature, an average BNL occurring in the classrooms throughout the school year was computed based on local weather data. Twenty of the classrooms were selected for more detailed BRIR measurements, due to their range of BNL and RT amongst the complete sample. The DFSM was calculated from the BRIR measurements with the source placed near the front of these classrooms facing various directions and the receiver in four typical student locations throughout the classrooms.

The results have provided insight on the relationship between unoccupied classroom acoustical conditions (which may be set as goals during the design phase of buildings) and elementary student achievement. The unoccupied BNLs are significantly negatively correlated to the language and reading subject area achievement scores for the fifth-grade students. In general then, elementary school classrooms should be designed with lower unoccupied BNLs to optimize student performance in the reading and language subject areas. This is similar to results from another school district in IA, in which high unoccupied BNLs occurred in elementary school classrooms with low reading comprehension achievement test scores (Ronsse and Wang 2010). Ronsse and Wang (2010) found that the negative correlations between BNL and reading comprehension were significant when controlling for the effects of poverty rates on achievement. However, in the present study in the NE school district, the correlations between BNL and achievement are not significant when controlling for the percent of students in each classroom receiving free or reduced-price lunches on achievement.

Differences in how the achievement scores were reported between the two school districts may account for some of the differences in the results between the studies. In the earlier study, the achievement scores were reported as 
pass rates (Ronsse and Wang, 2010), whereas the achievement scores in the NE school district were reported as normal curve equivalent, percentile rank, or scale scores. This may explain why stronger correlations were typically found between BNL and achievement in the Iowa school district than in the NE school district. Further research should examine if different acoustical recommendations should be made for schools constructed in areas with varying levels of poverty.

The results from the regression analyses with cooling BNL as a predictor variable for reading indicate that the classroom BNLs may range from 28 to $45 \mathrm{dBA}$ to meet the upper half of $\mathrm{NE}$ state targets for reading performance. Though this is a wide range of possible acceptable BNLs, the student reading scores were predicted to exceed the target levels for reading performance as the BNL was reduced beyond $28 \mathrm{dBA}$. These results were found based on average achievement scores from all students in the classrooms tested. However, even lower noise levels may be required for children with learning, language, or hearing deficiencies. Future research to address this issue will require school districts to provide individual student scores linked with demographic data, which was not possible in this investigation.

A negative correlation also occurred between DFSM, a metric for quantifying source localization ability, and achievement in the language subject area. This correlation was significant, even when controlling for the effects of student demographics on achievement. This suggests that the ability of children to accurately locate the sound source may be an important part of their learning process, and that DFSM may be a more robust metric to study rather than RT. More work on DFSM is suggested, however, so that the utility of metric (including its just noticeable difference, for example) is better understood.

One limitation of this study is the relatively narrow range of reverberation times across all of the classrooms tested. The average mid-frequency RT across the 500 and $1000 \mathrm{~Hz}$ octave bands ranged only from 0.2 to $0.4 \mathrm{~s}$ across all of the classrooms surveyed. To quantify the impact of RT on student achievement, investigations are needed in classrooms with longer reverberation times. Also, measurements of binaural metrics, including IACC, ILD, and left-to-right ear STI and DFSM differences, are needed in classrooms with a wider range of RTs to fully assess their impact on achievement.

Another area requiring further investigation is the effect of the classroom architectural features and furnishings on the DFSM. This study shows that DFSM is highly impacted by the source orientation relative to the receiver and the distance from the source to the receiver. It also suggests that DFSM is affected by the presence of reflective and diffusive surfaces altering the path from the source to the receiver. However, more research is needed to determine the suggested placement of reflective surfaces and room furnishings for optimal student achievement.

\section{ACKNOWLEDGMENTS}

The authors would like to thank the following individuals for their assistance with the research: the Papillion-La
Vista Public School District, especially Dave Harrill for providing assistance with the classroom mechanical system controls and Dr. Melanie Mueller for coordinating access to the detailed student achievement data; Dr. Walt Jesteadt and Dr. Daniel Valente at Boys Town National Research Hospital for allowing use of their KEMAR for measurements and testing; Dr. Peggy Nelson, Dr. Siu-Kit Lau, and Dr. Ralph Muehleisen for discussing and providing feedback on the project; and Christopher Ainley, Hyun Hong, Eric Powell, and Paul Sim for assisting with acoustical measurements and data compilation.

ANSI (2010). ANSI/ASA S12.60-2010 Acoustical Performance Criteria, Design Requirements, and Guidelines for Schools, Part 1: Permanent Schools (American National Standards Institute, New York).

Astolfi, A., and Pellerey, F. (2008). "Subjective and objective assessment of acoustical and overall environmental quality in secondary school classrooms," J. Acoust. Soc. Am. 123, 163-173.

Bistafa, S. R., and Bradley, J. S. (2000). "Reverberation time and maximum background noise level for classrooms from a comparative study of speech intelligibility metrics," J. Acoust. Soc. Am. 107, 861-875.

Bradley, J. S. (1986). "Speech intelligibility studies in classrooms," J. Acoust. Soc. Am. 80, 846-854.

Bradley, J. S., Reich, R. D., and Norcross, S. G. (1999). "On the combined effects of signal-to-noise ratio and room acoustics on speech intelligibility," J. Acoust. Soc. Am. 106, 1820-1828.

Bradley, J. S., and Sato, H. (2008). "The intelligibility of speech in elementary school classrooms," J. Acoust. Soc. Am. 123, 2078-2086.

Bradley, J. S., Sato, H., and Picard, M. (2003). "On the importance of early reflections for speech in rooms," J. Acoust. Soc. Am. 113, 32333244.

Choi, C. Y., and McPherson, B. (2005). "Noise levels in Hong Kong primary schools: Implications for classroom listening," Int. J. Disability Dev. Educ. 52, 345-360.

Dockrell, J. E., and Shield, B. M. (2006). "Acoustical barriers in classrooms: The impact of noise on performance in the classroom," Br. Educ. Res. J. 32, 509-525.

Elliott, L. L. (1979). "Performance of children aged 9 to 17 on a test of speech intelligibility in noise using sentence material with controlled word predictability," J. Acoust. Soc. Am. 66, 651-653.

Field, A. (2000). Discovering Statistics Using SPSS for Windows (Sage Publications, London), pp. 46-49, 101-102, 120.

Finitzo-Hieber, T., and Tillman, T. W. (1978). "Room acoustics effects on monosyllabic word discrimination for normal and hearing-impaired children," J. Speech Hear. Res. 21, 440-458.

Hodgson, M., and Nosal, E.-M. (2002). "Effect of noise and occupancy on optimal reverberation times for speech intelligibility in classrooms," J. Acoust. Soc. Am. 111, 931-939.

Houtgast, T. (1981). "The effect of ambient noise on speech intelligibility in classrooms," Appl. Acoust. 14, 15-25.

Houtgast, T., and Steeneken, H. J. M. (1985). "A review of the MTF concept in room acoustics and its use for estimating speech intelligibility in auditoria," J. Acoust. Soc. Am. 77, 1069-1077.

International Organization for Standardization (2008). ISO 3382-2 Acoustics-Measurement of room acoustic parameters-Part 2: Reverberation time in ordinary rooms (International Organization for Standardization, Geneva, Switzerland).

Jamieson, D. G., Kranjc, G., Yu, K., and Hodgetts, W. E. (2004). "Speech intelligibility of young school-aged children in the presence of real-life noise," J. Am. Acad. Audiol. 15, 508-517.

Jin, C., Corderoy, A., and van Schaik, A. (2004). "Contrasting monaural and interaural spectral cues for human sound localization," J. Acoust. Soc. Am. 115, 3124-3141.

Klatte, M., Hellbruck, J., Seidel, J., and Leistner, P. (2010a). "Effects of classroom acoustics on performance and well-being in elementary school children: A field study," Environ. Behav. 42, 659-692.

Klatte, M., Lachmann, T., and Meis, M. (2010b). "Effects of noise and reverberation on speech perception and listening comprehension of children and adults in a classroom-like setting," Noise Health 12, 270-282. 
Klatte, M., Meis, M., Sukowski, H., and Schick, A. (2007). "Effects of irrelevant speech and traffic noise on speech perception and cognitive performance in elementary school children," Noise Health 9, 64-74.

Knecht, H. A., Nelson, P. B., Whitelaw, G. M., and Feth, L. L. (2002). "Background noise levels and reverberation times in unoccupied classrooms: Predictions and measurements," Am. J. Audiol. 11, 65-71.

Lanham, J. W., III (1999). "Relating building and classroom conditions to student achievement in Virginia's elementary schools," Ph.D. dissertation, Virginia Polytechnic Institute and State University, Blacksburg, VA.

Moore, B. C. J. (2004). An Introduction to the Psychology of Hearing (Elsevier, New York), Chap. 7, pp. 233-267.

Okpala, C. O., Okpala, A. O., and Smith, F. E. (2001). "Parental involvement, instructional expenditures, family socioeconomic attributes, and student achievement," J. Educ. Res. 95, 110-115.

Picard, P., and Bradley, J. S. (2001). "Revisiting speech interference in classrooms," Audiology 40, 221-244.

Ronsse, L. M. (2011). "Investigations of the relationships between unoccupied classroom acoustical conditions and elementary student achievement," Ph.D. dissertation, University of Nebraska, Lincoln, NE.
Ronsse, L. M., and Wang, L. M. (2010). "Effects of noise from building mechanical systems on elementary student achievement," ASHRAE Trans. 116, 347-354.

Sato, H., and Bradley, J. S. (2008). "Evaluation of acoustical conditions for speech communication in working elementary school classrooms," J. Acoust. Soc. Am. 123, 2064-2077.

Shield, B. M., and Dockrell, J. E. (2004). "External and internal noise surveys of London primary schools,” J. Acoust. Soc. Am. 115, 730-738.

Shield, B. M., and Dockrell, J. E. (2008). "The effects of environmental and classroom noise on the academic attainments of primary school children," J. Acoust. Soc. Am. 123, 113-114.

Shield, B., Greenland, E., and Dockrell, J. (2010). "Noise in open plan classrooms in primary schools: A review," Noise Health 12, 225-234.

Shinn-Cunningham, B. G., Kopco, N., and Martin, T. J. (2005). "Localizing nearby sound sources in a classroom: Binaural room impulse responses," J. Acoust. Soc. Am. 117, 3100-3115.

Yang, W., and Bradley, J. S. (2009). "Effects of room acoustics on the intelligibility of speech in classrooms for young children," J. Acoust. Soc. Am. 125, 922-933. 